\title{
La comprensión como estructura existencial humana. Una ruta de la hermenéutica filosófica gadameriana ${ }^{1}$
}

\section{Understanding as a human existential structure. A route of Gadamerian philosophical hermeneutics}

\section{A compreensão como estrutura existencial humana. Uma rota da hermenêutica filosófica gadameriana}

Dr. Noé Héctor Esquivel Estrada²

Recibido: 9 de agosto de 2018 - Aprobado: 20 de septiembre de 2018

\begin{abstract}
Resumen
Este artículo tiene como objetivo proponer algunas reflexiones filosóficas de Gadamer que buscan dar respuesta al problema de por qué la comprensión no es simplemente un modo de conocer, sino que pertenece a la estructura existencial humana. Para lo cual se abordarán los tres puntos siguientes: 1. La perspectiva de la hermenéutica filosófica gadameriana en relación con la comprensión; 2. El ser de la comprensión como existencial humano, y 3. El rebasamiento de los límites de la comprensión impuestos por el conocimiento. Finalmente, me aproximaré a algunas reflexiones conclusivas.
\end{abstract}

Palabras clave: Hermenéutica - Comprensión existencial - Conocimiento - Interpretación - Experiencia

1 Este trabajo de investigación ha sido fruto de un curso-taller que se llevó a cabo en el Seminario Permanente de Hermenéutica, en el Instituto de Estudios sobre la Universidad, durante el semestre agosto-diciembre de 2017, en el que se leyeron y revisaron algunos textos de Gadamer.

2 Mexicano. Dr. en Filosofía por la Universidad Iberoamericana (Campus Ciudad de México). Profesor-Investigador del Instituto de Estudios sobre la Universidad, de la Universidad Autónoma del Estado de México. Contacto: noehectoresquivel49@gmail.com ORCID: https://orcid.org/0000-0003-1863-192X 


\begin{abstract}
This article aims to propose some philosophical reflections by Gadamer in order to answer why understanding is not simply a way of knowing, but belongs to the human existential structure. It approaches three points: 1. Perspective of Gadamerian philosophical hermeneutics in relation to understanding; 2 . Understanding being as human existential, and 3. Overcoming limits of understanding imposed by knowledge. Finally, it presents some conclusive reflections.
\end{abstract}

Keywords: Hermeneutics - Existential understanding - Knowledge - Interpretation - Experience

\title{
Resumo
}

Este artigo tem como objetivo propor algumas reflexões filosóficas de Gadamer que buscam dar resposta ao problema de por que a compreensão não é simplesmente um modo de conhecer, senão que pertence à estrutura existencial humana. Para aquilo, são abordados os três pontos seguintes: 1. A perspectiva da hermenêutica filosófica gadameriana em relação com a compreensão; 2 . O ser da compreensão como existencial humano, e 3. A excedência dos limites da compreensão impostos pelo conhecimento. Finalmente, aproximar-me-ei de algumas reflexões conclusivas.

Palavras-chave: Hermenêutica - Compreensão existencial - Conhecimento - Interpretação - Experiência

\section{Cuestiones fundamentales de la hermenéutica filosófica gadameriana en conexión con la comprensión}

En su trabajo "La hermenéutica como tarea teórica y práctica (1978)" Gadamer comenta que el término "Hermenéutica" es muy antiguo; pero, a finales del siglo XVIII y principios del XIX se le reconocía comúnmente como "la facultad práctica del comprender" desde una perspectiva eminentemente humana, es decir, como la intuición y perspicacia para comprender y guiar a los demás. Razón por la que a esta práctica se la vinculaba directamente con la misión del director espiritual. El mismo Schleiermacher, promotor de la hermenéutica como método propio de las ciencias del espíritu, señalaba que el comprender no sólo se aplicaba a los textos sino también a las personas. Gadamer indica que la hermenéutica no sólo es un método adecuado para un 
grupo de ciencias (a la manera de Schleiermacher), sino "sobre todo una capacidad natural del ser humano"3 (1992 293), que le permitirá pensar y actuar adecuadamente en la vida (como experiencia humana del mundo). Pero, el origen de la hermenéutica filosófica moderna se vincula a una preocupación epistemológica circunscrita al problema de la teoría de la ciencia, en la que el "método hermenéutico" adquiere autonomía para la justificación de las ciencias del espíritu. Debido a esta limitación, dice Gadamer, es que la hermenéutica filosófica se orienta hacia la búsqueda de la comprensión e interpretación en su sentido más originario.

Sabemos que Heidegger, después de escribir Ser y tiempo, abandona la filosofía hermenéutica por visualizarla con pretensiones de fundamentación metafísica; pero es posible que tal aseveración haya sido producto del "olvido" de la finitud de la existencia humana que anulaba tal posibilidad. Es por ello que, en su carta a O. Pöggeler ${ }^{4}$, le dice que la "filosofía hermenéutica" es cosa de Gadamer. A pesar de esto, no podemos olvidar que el origen de la filosofía hermenéutica está en Heidegger y que Gadamer es "deudor" de este pensamiento. Desde este contexto, es comprensible aquella expresión de Habermas al referirse a la hermenéutica gadameriana a la que denomina la "urbanización de la provincia heideggeriana".

Cuando Gadamer nos habla de su acercamiento a la hermenéutica nos relata su propia experiencia. ¿Qué cosa quiere decir esto? Que su decisión y primer encuentro con la filosofía de su época -el neokantismo, el positivismo, el pensamiento de Husserl (fenomenología)- le suscitaron cierta sospecha por sus marcadas pretensiones sobre el conocimiento de la realidad. Frente a tales posturas, asume una actitud respetuosa pero crítica, de análisis y de cuestionamiento. No es hasta su encuentro

3 Sobre el sentido del método lo acotaremos, de manera más precisa, un poco más adelante. En el cuerpo del artículo cito en "entrecomillado" el trabajo específico de Gadamer, al igual que en las notas a pie de página donde, además, se refiere la obra en la que se encuentra ese texto; el propósito es tener un acercamiento más puntual del trabajo consultado y fecha de su producción.

4 Del 5 de enero de 1973. 
con Heidegger que se despierta en él una nueva inquietud por el pensamiento: regresar a sus orígenes con tal inocencia y olvido de sí mismo (Gadamer 1992375 y ss.). Éste se descubre como requisito propio de la hermenéutica, para no caer en visiones y posiciones dogmáticas. No se trata de formular nuevas conceptualizaciones, sino de su propia experiencia dialogal con la tradición filosófica. Los conceptos definen, delimitan, determinan y, en última instancia, hacen que quedemos prisioneros en los presupuestos de los conceptos. Por tanto, el camino es el diálogo, en el que la posibilidad de comprensión se convierte en una conversación interminable. "Desde esta perspectiva la filosofía «hermenéutica» se entiende, no como una posición «absoluta», sino como un camino de experiencia" (Id. 399).

Su reconocimiento a Heidegger se hace manifiesto de manera amplia y sincera en el siguiente texto:

Pero lo más importante lo aprendí de Heidegger. Recuerdo sobre todo el primer seminario en el que participé. Fue el año 1923, todavía en Friburgo, sobre el libro sexto de la Ética a Nicómaco. La phronesis, la areté de la «razón práctica», allo eidos gnoseos, «un género de conocimiento diferente», fue entonces para mí una palabra mágica. Cierto que me sonó a provocación el día en que Heidegger analizó la distinción entre tejne y phronesis y declaró a propósito de la frase phroneseos de ouk esti lethe (en la racionalidad no hay olvido): «eso es la conciencia moral» (Id. 381).

Heidegger define la estructura ontológica del "ser-ahí" humano como la comprensión del ser que corresponde a la acción clarificadora de la razón. Así lo entiende Gadamer: "Heidegger trasladó así la hermenéutica desde la problemática de los fundamentos de las ciencias del espíritu al centro de la filosofía misma. La paradoja de una hermenéutica de la facticidad contenía a nivel ontológico la crítica al concepto de conciencia, de objeto, de hecho y de esencia, de juicio y de valor" (Ibíd.). Desde esta perspectiva, Heidegger asume la historicidad y temporalidad del "ser-ahí" como camino que orientará la pregunta por el sentido del ser. 
La influencia que Gadamer recibió para la elaboración de su filosofía hermenéutica, como él mismo reconoce en Verdad y método, fue el horizonte histórico de Dilthey, la descripción fenomenológica de Husserl y la hermenéutica de la facticidad de Heidegger; sin omitir la presencia de Hegel, Platón y Aristóteles.

Cuando pensamos la hermenéutica como un modo de ser y vivir humanos recuperamos su carácter fenomenológico existencial que nos lleva a pensar en el ser de la vida humana. La fenomenología de la vida fáctica asume una postura crítica ante el optimismo de la razón. El sentido crítico de esta visión hermenéutica nos coloca ante algunas interpelaciones como las siguientes, entre otras, ¿cuál es el sentido de la vida humana hoy? ¿Cómo captar la inmediatez de las experiencias humanas en el ámbito de una sociedad fragmentada y sin valores? ¿Cómo reorientar la vida hacia un interés de emancipación en favor de una sociedad justa y responsable? Günter Figal, en términos sencillos, nos revela el camino seguido por Gadamer: "Y eso que lo que Gadamer ha visto y enseñando es ya conocido y está fuera de discusión: que la existencia humana queda cumplida en el diálogo, que todo comprender va ligado a la conciencia de los propios límites, al reconocimiento del otro en su ser extraño, y tiene que incluir siempre la posibilidad de que el otro tenga la razón" (2003 111). Cuestiones inapelables para todo aquel que se precie de adoptar a la hermenéutica dialogal, existencial y finita como camino del pensar. El sometimiento de la propuesta gadameriana al análisis crítico de ninguna manera le resta su impacto en el campo filosófico, antes bien, el reconocimiento de sus propios límites es parte constitutiva de la "historia efectual" a la que el propio Gadamer concede un lugar importante dentro de su hermenéutica filosófica.

El carácter filosófico de la hermenéutica puede entenderse, según Gadamer, en los siguientes términos:

La hermenéutica es filosófica porque no puede limitarse a ser el arte de entender las opiniones del otro. La reflexión hermenéutica implica que en cada comprensión de algo o de alguien se produce una autocrítica. El que comprende, no adopta una posición de superioridad, sino que recono- 
ce la necesidad de someter a examen la supuesta verdad propia. Esto va implicado en todo acto comprensivo y por eso el comprender contribuye siempre a perfeccionar la conciencia histórico-efectual (1992 177).

En esencia, se trata de reconocer quiénes somos, dónde estamos y hacia dónde pretendemos ir. En esto consiste la conciencia históricoefectual, y la hermenéutica que se ocupa de este asunto es la hermenéutica existencial. He de señalar, por tanto, que la hermenéutica a la que Gadamer se refiere no consiste en un proceso metódico para la comprensión e interpretación de textos, sino se trata de una hermenéutica vital, por lo que los constitutivos de esta propuesta hermenéutica tienen que ver con aspectos vitales-existenciales. En su artículo "Tras las huellas de la hermenéutica" (1994) insiste en que no se trata de un método que deban seguir las ciencias sociales para su justificación frente a las ciencias de la naturaleza, sino "La hermenéutica se refiere más bien a todo el ámbito de comunicación intrahumana" (Gadamer 1998 85). El objetivo de todo modo de comunicación intrahumana es el entendimiento. Entendimiento que no es coincidencia sino acuerdo en la divergencia mediada por la conversación.

Considero que algunas de las orientaciones fundamentales de la hermenéutica gadameriana las expone de manera brillante y clara Agustín Domingo Moratalla, cuando comenta que la hermenéutica ya no es el "arte de la interpretación" sino el "arte de poder no tener razón". Éste se constituye en un principio hermenéutico con el cual podemos establecer una auténtica relación dialogal con el otro. No es posible entendernos bajo el régimen del sometimiento o del dominio sobre el otro; el entendimiento se realiza en la dirección de un encuentro dialogal y vivencial. Así la hermenéutica asume una orientación eminentemente existencial; tampoco la hermenéutica filosófica transita bajo el régimen del método con pretensiones de dominio y alcances definitivos.

El siguiente fragmento puede tomarse como advertencia para ver que nuestra convivencia humana no es tan humana como suponemos. Es así que lo humano solo puede entenderse de manera comunitaria. Ser humano es apertura a la donación y a la recepción. 
Únicamente de este modo tendremos la posibilidad de apartarnos para que se aprecie también al otro. Yo pienso que lo que interesa es llegar en cierto modo a olvidarse de uno mismo. Y ésa es una de las grandes bendiciones del arte, una de las grandes promesas de la religión, y finalmente, en términos generales, una de las condiciones fundamentales para la convivencia de los hombres de una manera humana (Gadamer 2001 147).

Habrá que poner atención para pensar qué significa eso de lo humano. La hermenéutica, puesta en práctica por Gadamer, no se limita al ejercicio de la interpretación, sino que conlleva el proceso de transformación de sí mismo, experiencia vital en oposición a la instrumentalización de la interpretación. Así lo sostiene Jean Grondin: "Interpretar y entender no son únicamente procesos que caracterizan a las ciencias humanas, sino que afectan además a toda nuestra manera de ser" (2003 33).

Para trascender el sentido de encuentro y diálogo con lo otro, Gadamer reflexiona y se pregunta sobre el significado de "lo dado", y dice: "¿Qué es lo dado? Sólo quien no responda a esta pregunta con la frase: aquello que se puede medir, sólo quien permanezca abierto a este tipo de preguntas, sólo ese sabrá lo que es la filosofía hermenéutica" (1998 152) 5 .

Desde esta perspectiva, se puede entender que la comprensión (que trataremos a continuación) no es un acto de conocimiento, no es una competencia para saber quién tiene el mayor o menor grado de conocimientos, no es una lucha por el apoderamiento de la verdad, sino que comprender es nuestro modo de existir en el mundo. De este modo, el autor reconoce que su visión de la hermenéutica filosófica rebasa los límites de la interpretación de textos para establecerse como hermenéutica de la existencia. En términos de Heidegger podríamos decir que el hombre es un ser hermenéutico: un ser que se interpreta 
a sí mismo e interpretante. La hermenéutica se constituye así en un modo de ser humano.

El quehacer hermenéutico alcanza su realización plena en-la-relación. Relación con el mundo objetual (referencial), con el mundo social (intercomunicación) y con el mundo subjetivo (autocomprensión). Relación que imposibilita el aislamiento o la fragmentación. A modo de ejemplo: como ausencia de integración podríamos señalar el quehacer llevado a cabo por la ciencia positiva, que sólo se relaciona con el mundo objetual; del mismo modo, la intercomunicación sin referencia al mundo real desembocaría en pura subjetividad, y la autocomprensión envuelta en sí misma nos conduciría al solipsismo.

El hombre no es un ser solitario. Para Gadamer el rumbo de la hermenéutica es el encuentro con el otro y con lo otro, que viene a modificar no sólo la propia cosmovisión sino el mismo modo de ser. En sentido propio, hermenéutica es un encuentro dialogal que transforma el modo de ser y vivir humanos. Como "arte de entender", se trata de aprender a convivir con los demás respetando sus diversas formas de vida y convicciones; "el arte de entender" nos exige, al mismo tiempo, respetar las formas de vida propias de todos los seres vivos y aprender a convivir en y con la naturaleza. " $i$ Entender quiere decir que yo soy capaz de considerar y ponderar lo que la otra persona piensa! ¡Podría tener razón en lo que dice o quiere decir! Por tanto, entender no es domeñar y violentar lo que tenemos delante, domeñar a la otra persona $y$, en general, al mundo que tenemos como objeto frente a nosotros" (Gadamer 2001 144) 6 . Sin embargo, en esta capacidad de entender se abre también la posibilidad y el peligro de dominar y objetivar, aspectos que analiza y critica fuertemente en casi toda su obra. De la interrelación nace la solidaridad, entendida como capacidad para buscar y compartir convicciones humanitarias más allá de necesidades e intereses particulares. "Yo opino que, a pesar de todos nuestros progresos tecnológicos y científicos, no hemos aprendido suficientemente a saber vivir unos

6 Gadamer, H. "De la palabra al concepto" (1995). 
con otros y con tales avances." (Id. 147). No hemos aprendido a ser solidarios. "Esa crisis dio otro rumbo al sentido de la comprensión. Ahí está el otro, que rompe mi egocentrismo dándome a entender algo" (Gadamer 1992 17).

Recordemos que la hermenéutica es el arte del entendimiento. Sin embargo, reconocemos que es difícil ponerse de acuerdo sobre cuál sea el quehacer y los mismos problemas que entraña la hermenéutica, de manera especial cuando los conceptos de "ciencia", "crítica" y "reflexión" preceden el debate.

Vivimos en una época en la que la ciencia trae consigo el progresivo dominio de la naturaleza y regula la administración de la convivencia humana, y este orgullo de nuestra civilización, que corrige incansablemente los fallos de sus éxitos y crea constantemente nuevas tareas de investigación científica que fundamenta a su vez el progreso, la planificación y la remoción de los daños, despliega el poder de una auténtica ofuscación (Id. 243).

Situación que reclama que nuestra actitud no puede ser neutral, pues tal actitud puede desembocar en una aceptación resignada y ciega o, por el contrario, en una crítica sin fundamento que, del mismo modo, arriba a la ceguera. Conscientes del predominio de la ciencia positiva, nos vemos en la necesidad de formular un saber distinto del de la ciencia moderna, que sea el que oriente la conducta y vida humanas. Se trata de un "saber crítico", no de un "arte" en el sentido de aprender las reglas para hablar bien. La hermenéutica filosófica, como arte del entendimiento, asume un "saber crítico".

Podemos reconocer que el propósito de la hermenéutica es descubrir la capacidad de los interlocutores para llegar a entendimientos mutuos, con acercamientos y distanciamientos. La comunicación dice algo, pero no agota la totalidad de lo dicho. Siempre hay expectativas de nuevos entendimientos, lo que revela la riqueza tanto de la palabra como del discurso. "El arte de comprender consiste seguramente y ante todo en el arte de escuchar. Sin embargo, a ello hay que añadir la posibilidad de que el otro pueda tener razón" (Gadamer 1998 227), 
dispositivo que hace posible la comprensión y la conversación pues toda comprensión es conversación.

La ontología hermenéutica no pude sustentarse en el paradigma de la relación sujeto-objeto sino, según palabras de Moratalla, en una "ontología comunicativa desde la que se replantea en sus mismos fundamentos la filosofía de la reflexión y por ello sólo puede ser modesta, no triunfante y ya siempre metacrítica" (Moratalla 1991 243). Hemos de advertir que la filosofía de la reflexión no puede identificarse con la filosofía de la conciencia. Cuando la filosofía de la conciencia se identifica con la filosofía de la reflexión, entonces ésta queda atrapada por los límites de los conceptos, por lo que debe ser superada por una filosofía de la compresión-interpretación. "El giro ontológico de la hermenéutica ha permitido que pensemos unitariamente el proceso del conocimiento y nuestro estar-en-el-mundo como un proceso unitario por el que todo comprender es interpretar" (Ibíd. 234). El problema de la verdad o de la interpretación verdadera se encuentra en el camino correcto cuando se descubre el proceso unitario de la comprensión-interpretación como acontecimiento histórico-vital, sin acentuar la carga de la subjetividad o de la objetividad; por eso: "La interpretación verdadera es aquella en la que se «realiza la comprensión»" (Id. 235).

Es tarea de la hermenéutica detectar las condiciones que conforman tanto la visión del mundo como la experiencia del mismo, a sabiendas de que tal visión y experiencia siempre son limitadas, lo cual nos lleva a evitar pronunciamientos o concepciones totalitarias o absolutas. Así, la pluralidad de sentidos y significaciones en nuestras conversaciones se ven precedidas por la naturaleza finita del ser humano. Con lo cual se resuelve el problema de la univocidad.

Para Gadamer, es competencia de la hermenéutica tender un puente dialogal entre la naturaleza humano-histórica para lograr un entendimiento común. Pero no es posible entender al otro si uno u otro no quieren entender o no permiten que se les diga algo. Solo en la disponibilidad del mutuo entendimiento se finca un dispositivo ético: querer entender lo que el otro me dice es estar dispuesto a escuchar algo distinto de lo que pienso o quiero escuchar. En esta 
disposición del mutuo entendimiento se encuentran tanto la verdad como la ética hermenéutica, aspectos sustantivos de la comprensión. Escuchar y entender al otro lleva a la confrontación consigo mismo, con los propios pensamientos y valoraciones. Razón por la que el dispositivo al entendimiento mutuo exige apertura a lo nuevo y distinto. El "diálogo" es vacuo cuando uno de los interlocutores cree saberlo todo.

En síntesis, podemos recuperar el siguiente pensamiento de Gadamer: "La hermenéutica no significa tanto un procedimiento cuanto la actitud del ser humano que quiere entender a otro o que como oyente o lector quiere entender una manifestación verbal. Siempre es, pues: entender a un ser humano, entender este texto concreto" (2001b 149). Esta convicción marcó el hilo conductor de toda la vida y obra de Gadamer, plasmada en su modo de ser, vivir y trasmitir su pensamiento. Hermenéutica dice siempre relación al otro, al encuentro, al diálogo y comprensión con el otro. Se trata, en definitiva, de un encuentro vital; de un encuentro humano entre humanos y, también, con lo no-humano.

Pasemos a explorar qué es la comprensión y sus implicaciones en el ser de la existencia.

\section{El ser de la comprensión como existencial humano}

Hemos comentado ya que la hermenéutica filosófica de Gadamer tiene sus raíces en el pensamiento heideggeriano. Sus reflexiones sobre la comprensión también nos remiten a Heidegger; por eso, en este momento nos vemos en la necesidad de hacer esta recuperación. El retorno a la ontología del ser es, para Heidegger, el fundamento de la comprensión histórica. El hombre es esencialmente un ser histórico, temporal y finito. La comprensión es estructura humana de la misma naturaleza que su ser: histórica, temporal y finita. Desde esta conformación, la conciencia no puede identificarse con la comprensión, pues a la conciencia le precede la historia. "En la comprensión no se realiza una proyección de significado, sino la manifestación ontológica de la cosa misma («die Sache»). Ésta se hace patente por sí misma; la 
comprensión no crea, sino que permite tal anticipación del ser («Lógos apofántico»)" (Maceiras y Trebolle 1990 49).

El comprender no es otra cosa que permitir que el ser de las cosas se desvele; en este sentido, para Heidegger, le compete permitir desvelar las posibilidades de existencia del "Dasein". "Este enraizar la «historicidad» de la comprensión en la temporalidad intrínseca de la existencia humana corresponde al programa de Heidegger de interpretar la verdad y la historia a partir de la temporalidad absoluta del ser... La tesis de Heidegger es: el ser mismo es tiempo" (Id. 52).

Dentro de las estructuras originarias, que Heidegger le reconoce al ser-ahí humano, está la comprensión. Somos originariamente seres de comprensión. El comprender, dice Heidegger: "Si lo interpretamos como un existencial fundamental, con ello se muestra que este fenómeno es comprendido como un modo fundamental del ser del Dasein" (Heidegger 2003 166-167). Se le reconoce como constitutivo ontológico del ser del Ahí.

La aperturidad del comprender despliega su ser de potencialidades en su estar-en-el-mundo. "El comprender es el ser existencial del propio poder-ser del Dasein mismo, de tal manera que este ser abre en sí mismo lo que pasa consigo mismo" (Id. 168). El comprender tiene la estructura existencial del proyecto, es decir, en cuanto Dasein él mismo se ha proyectado y es proyectante de su existencia. El Dasein puede reconocerse a partir de su estar-en-el-mundo. El "autoconocimiento" del Dasein no se refiere a un conocimiento de algo concreto sino a su estar-en-el-mundo; a partir de este estar-en-el-mundo, en cuanto proyecto, es que él puede conocerse.

En la analítica existencial, la comprensión, tal como la entiende y expone Heidegger, es comprensión de la existencia, en la que temporalidad e historicidad son el modo de ser propio de la comprensión misma. La estructura de la comprensión es histórico-temporal y, como tal, su modo de realización es también en el tiempo y en la historia. En estos términos, reconoce Heidegger, la comprensión es la forma originaria del estar ahí, de ser-en-el-mundo. Comprender es el carácter óntico original de la vida humana misma. Por eso el comprender e interpretar 
solo es posible donde entra la totalidad de la estructura existencial. La siguiente cita nos muestra el carácter histórico-temporal del estar ahí, de la existencia: "La analítica existencial del estar ahí no implica según Heidegger ningún ideal existencial histórico determinado" (Gadamer 1984 328).

Nos parece claro que la hermenéutica finca sus bases en la historicidad y finitud de la razón humana, por lo que la interpretación que realiza rehúye a la recurrencia de criterios últimos, definitivos, y sustenta su objetivo en la comprensión que somos: comprensión finita e histórica.

En este tenor la hermenéutica no es un método o un procedimiento de interpretación, sino un modo de ser propio del ser del Dasein. Dice López Sáenz: "Por el contrario, como nos enseña la hermenéutica ontológica de Heidegger, la comprensión interpretativa es un existenciario, es decir, al ser mismo le compete intentar comprender su ser; este comprender es el ser del Dasein" (2012 450-451), de donde se infiere que no se trata de un atributo o de un complemento del ser del Dasein, sino que la comprensión es su modo de ser propio, que se pregunta por su ser. Así arribamos al carácter ontológico de la comprensión. Digamos que se trata de una ontología hermenéutica, existencial. La autora hace una diferenciación entre la fenomenología husserliana y la heideggeriana como antecedente a la consideración de la ontología hermenéutica-existencial. Dice al respecto: "La fenomenología trascendental husserliana se convierte con Heidegger en fenomenología hermenéutica. La primera tarea de ésta será la fenomenología del ser del Dasein o el análisis de sus estructuras ontológicas fundamentales y de los modos de ser de los otros entes en relación con él" (Ibíd.). Si la comprensión es un modo de ser humano originario, ésta necesariamente tiene que ser un modo de ser con el otro y lo otro. Pues la comprensión es un modo de ser humano en relación. "La fenomenología heideggeriana del Dasein es, además, hermenéutica en tanto comprensión del sentido o analítica de la existenciariedad de la existencia" (Ibíd.). La comprensión es un existenciario ineludible del Dasein y, consecuentemente, la interpretación no es otra cosa que la automanifestación y comprensión del ser (de Dasein). "La interpretación no es posterior a la comprensión, sino el proceso de 
la misma por la vía de su apropiación, no de su distanciamiento con fines explicativos" (Id. 453). Por eso la interpretación no tiene por objetivo describir los objetos externos a nosotros mismos, sino es una auto-manifestación de nuestro modo-de-ser-con.

Heidegger, Gadamer y Ricoeur coinciden en el carácter existencial de la comprensión hermenéutica, con lo que abandonan la visión instrumental de la misma. El conocimiento, como tal, no es un elemento sustancial de la comprensión, aun cuando no se anula, pero tampoco puede la comprensión restringirse a él.

Toda comprensión asienta sus bases sobre la corporeidad; no es suficiente la cabeza (el pensar) se requiere de los demás sentidos: los ojos, desde donde hacemos una lectura de nuestro mundo; los pies, que nos ubican en el lugar y en el contexto de nuestra vida; el oído, como extensión de nuestra historia; en fin, todo lo que constituye nuestro ser que nos permite experienciar nuestro mundo. Comprendemos a partir del mundo que habitamos.

Para Heidegger, como ya se mencionó, la comprensión es un existenciario, es decir, es un constitutivo originario del ser de la existencia humana. Es originaria porque es dada con el ser de la existencia y, en esos mismos términos, debe entenderse que la interpretación es de la propia existencia, es decir, es auto-comprensión y la comprensión humana del ser, reconociéndose así la primacía de la comprensión de la existencia que nos conduce a la comprensión del ser. Por su parte, Gadamer hace una recuperación del carácter ontológico existencial de la comprensión, afirmando que ésta pertenece a la experiencia humana del mundo.

Ante la multiplicidad de conceptos que surgen acerca de qué es la comprensión -entender, conocer, vivir, ser en el mundo, empatía, diálogo, relación, etcétera-, Gadamer la retomará y desarrollará ampliamente exponiéndola en los siguientes términos:

Si consideramos el verdadero alcance que posee el concepto de comprensión por el uso lingüístico, la expresión «círculo hermenéutico» sugiere en realidad la estructura del ser-en- 
el-mundo, es decir, la superación de la escisión entre sujeto y objeto en la analítica trascendental del ser-ahí llevada a cabo por Heidegger (1992 320).

Esta superación dicotómica de sujeto-objeto nos impele a reconocer la comprensión como el modo de ser-en-el-mundo; con lo cual se le suprime el carácter instrumental u objetual. La comprensión no es una herramienta de uso lingüístico sino un constitutivo del serahí humano. Ontología hermenéutica existencial que se expresa en las manifestaciones de la vida y cuyo desarrollo se hace patente en el comprender-se e interpretar-se, cuestión que no se resuelve epistemológicamente, en un acto de conocimiento ni en una consideración teorética, sino en un ejercicio práctico, en su modo de ser en-el-mundo y en-relación-con, lugares donde se revela el carácter ontológico de la comprensión.

Si la comprensión es un modo de ser humano originario, ésta necesariamente debe ser un modo de ser con el otro y lo otro. Es el modo de ser humano en-relación. Por eso la interpretación no tiene como finalidad describir los objetos externos a nosotros mismos, sino que su expresión es una auto-manifestación de nuestro modo-de-ser-con.

En un homenaje, con motivo de la muerte de Gadamer (2002), Silva Camarena escribe un breve texto titulado In memoriam, en el que hace un pequeño recorrido trayendo a la memoria algunas vivencias de Gadamer relatadas en su obra Mis años de aprendizaje. En este breve escrito Silva Camarena nos brinda una imagen clara y congruente de la vida y obra de Gadamer. En él no podemos separar la teoría de la praxis, el pensamiento de la acción; quizá el reconocimiento a este modo de vida puede ser su mayor homenaje. Silva titula su trabajo "EI arte de comprender y hacer comprender", cosa que revela el constante interés y la actitud vital de Gadamer por el otro y muestra que no es suficiente con elaborar una teoría de la comprensión, sino es necesario reconocer que la comprensión alcanza su plenitud en la comprensión del otro. Comprender al otro no solamente es un arte difícil, también es fundamentalmente una tarea humana que no puede eludirse o postergarse. Comprender al otro es parte de nuestro ethos humano. Por eso le vienen bien aquellas palabras que Heidegger pronunció 
con motivo de la muerte de Scheler: "Una vez más, una senda de la filosofía se pierde en la oscuridad" (Silva 2002 45).

La comprensión humana, como modo de ser originario, es el medio por el cual éste proyecta su ser hacia posibilidades. Por eso, hablar del carácter ontológico de la comprensión no nos refiere a un modo de ser dado de una vez y para siempre, situación que revela la estaticidad del ser, sino al modo de ser que proyecta su ser hacia posibilidades; es decir, es en el comprender, interpretar y aplicar donde el ser humano construye y desarrolla su ser.

Dar seguimiento a la comprensión a través de la obra magna de Gadamer, Verdad y método, y de muchos de sus textos más, sólo es posible haciendo un rastreo puntual de cada uno de los temas en los que está inmersa la comprensión, lo cual nos revela la amplitud y riqueza que el autor le reconoce, a saber:

1. La historicidad de la comprensión como principio hermenéutico, en la que se incluyen: a) el círculo hermenéutico y el problema de los prejuicios; b) los prejuicios como condición de posibilidad para la comprensión; c) el significado hermenéutico de la distancia temporal, y d) el principio de la historia efectual.

2. La recuperación del problema fundamental hermenéutico, en el que se insertan: a) el problema hermenéutico de la aplicación; b) la actualidad hermenéutica de Aristóteles, y c) el significado paradigmático de la hermenéutica jurídica.

3. El análisis de la conciencia de la historia efectual, que abarca: a) los límites de la filosofía de la reflexión; b) el concepto de experiencia y el de experiencia hermenéutica, y c) la primacía hermenéutica de la pregunta (programa de vida humana).

En la analítica existencial la comprensión, entendida y expuesta por Heidegger y Gadamer, es comprensión de la existencia en la que la temporalidad e historicidad son el modo de ser propio de la comprensión originaria. La estructura de la comprensión es histórico-temporal y, como tal, su modo de realización es también en el tiempo y en la historia. 
El comprender tiene, además, la estructura existencial de proyecto, es decir, en cuanto Dasein él mismo se ha proyectado y es proyectante en el curso de su existencia. El Dasein puede reconocerse a partir de su estar-en-el-mundo. El "autoconocimiento" del Dasein no se refiere a un conocimiento de algo concreto, a modo de un objeto, sino a su estar-en-el-mundo; a partir de su estar-en-el-mundo, en cuanto proyecto, es que él puede conocerse.

La verdadera naturaleza de la comprensión no consiste en saber cómo se puede comprender el "ser", sino cómo la comprensión es "ser". El primer aspecto se refiere a un ejercicio conceptual acerca del "ser", en el que la comprensión del ser constituye la nota existencial del ser-ahí humano: somos seres humanos que comprendemos. El segundo, es totalmente diferente, porque la pregunta se dirige al ser del "ser-ahí" que se autocomprende, sin que con ello se pretenda llegar al resultado de la operación objetivante de la conciencia, a la manera de la fenomenología husserliana. Aquí la comprensión misma se integra en la problemática ontológica. La comprensión es un modo del acontecer mismo del ser.

¿Qué relación o interdependencia se da entre la comprensión y el ser? ¿Qué entre la comprensión y el ente? La reflexión heideggeriana nos conmina a reconocer que la comprensión, como estructura propia del Dasein, es la condición de posibilidad del ente. Así lo propone el autor: "...tan sólo si la comprensión del ser es, se hace accesible el ente en cuanto ente; tan sólo si un ente que tiene el modo de ser del Dasein es, la comprensión del ser es posible como ente" (Heidegger 2003 233). La pregunta por el sentido del ser ha sido y sigue siendo el problema que ha acompañado a toda reflexión filosófica, así lo testimonia la historia de la filosofía.

Como hemos visto, es evidente la presencia e influencia de Heidegger en el pensamiento de Gadamer, pero en muchos puntos éste va más allá de su maestro. Mientras a Heidegger le preocupa e interesa abordar el tema de la estructura de la comprensión -como estructura originaria del Dasein-, Gadamer centra su reflexión en la historicidad de la comprensión. La comprensión es el modo de realizarse históricamente el ser humano. López Sáenz dice que la 
hermenéutica gadameriana no es una variante de la hermenéutica heideggeriana, hay grandes diferencias entre ellas, entre las que cabe señalar las siguientes: "Fundamentalmente el giro lingüístico que imprime a la ontología heideggeriana. Por otro lado, pone entre paréntesis los temas más existenciales de Heidegger (angustia, nada, autenticidad, futurización, muerte, etc.); lejos de proclamar como su predecesor el fin de la metafísica por haber velado el ser, confía en la pertenencia a una tradición para orientarse hacia la verdad (...)" (2012 474-475).

Más allá del proceso unitario de la comprensión e interpretación expuesto por la hermenéutica romántica, Gadamer integra a este proceso la aplicación, que es el momento en el que se realiza, de manera práctica, la comprensión. De este modo, integra en su propuesta el círculo hermenéutico de la comprensión-interpretación-aplicación, sin que una de ellas tenga o ejerza prioridad sobre las otras. Así, toda comprensión es aplicación; toda interpretación es comprensión, y toda aplicación es comprensión-interpretación. En este proceso unitario de comprensión-interpretación-aplicación, ésta última no puede reducirse a una actividad concreta y particular, sino es el modo propio de realización en la vida del Dasein, lo mismo que es la interpretación. Comenta Agustín Domingo Moratalla al respecto:

La interpretación ya no es sólo de textos puesto que está en juego la comprensión y la interpretación humana. En el fondo de esta pretensión de unidad práctica y fundante se encuentra la capacidad del hombre para un contacto comprensivo con los hombres. Es más, esto significa, la articulación de una capacidad de escucha y recepción que, en el caso de la comprensión de textos, se convertirá en respuesta a una tradición que nos interpela (1991 230).

Esta forma de ver, entender y vivir hace patente el carácter ontológico-humano de la comprensión-interpretación-aplicación, con sus respectivas implicaciones histórico-humanísticas, culturales y sociales. Somos seres en-relación-con-el otro y con-lo otro. La aplicación como actualización de sentido de un texto rebasa los límites de la "interpretación puramente textual" y tiene implicaciones humanas, 
prácticas, asumidas como la capacidad de relacionarnos-con-el-otro y lo-otro. Así se puede reconocer a la aplicación con un sentido humano-existencial.

Dentro de esta estructura circular de la hermenéutica (comprensióninterpretación-aplicación), la interpretación no puede ser concebida como un accesorio del conocimiento o de la comprensión, porque está estrechamente unida a lo dado; es más, lo dado es inseparable de la interpretación: "Una reflexión fenomenológica que parta de la conciencia y de la percepción pura encuentra aquí sus límites. Esto significa que la interpretación en tanto que comprensión-de-algocomo-algo forma la estructura originaria del "ser-en-el-mundo»" (Id. 233).

Al preguntarnos sobre la naturaleza de la comprensión, como acto constitutivo del ser humano, es interesante recuperar el concepto expuesto por Jean Grondin, que lo expone como la participación en una verdad hermenéutica, en una verdad de formación que nos forma y transforma. Es una hermenéutica de la facticidad fincada en la historicidad del ser humano. "Ahora bien, para una hermenéutica de la facticidad ese entender es tan fundamental, que no puede designarse simplemente como el procedimiento cognitivo y, por tanto, metodologizable de las ciencias humanas. Tiene sus raíces más profundas, porque ahora encarna «la forma originaria de realización del 'ser-ahí, del ser-en-el-mundo»" (Grondin 2003 124).

Hablar de la comprensión histórica no consiste en la recuperación del pasado histórico y tampoco de la reconstrucción de la historia, sino de la continuación responsable de la misma, hacer historia. De este modo recuperamos el sentido del ser histórico que somos nosotros mismos. Precisamente, el término de la aplicación hermenéutica está vinculado con el horizonte de la acción y responsabilidad históricas. Somos seres históricos de comprensión, es decir, de responsabilidad transformadora de la historia. Por eso, para Gadamer el círculo hermenéutico del comprender-interpretar-aplicar está íntimamente vinculado con el quehacer histórico responsable. Toda comprensión es aplicación, al igual que la interpretación, y todas ellas con una proyección transformadora de la historia. A este procedimiento le llamamos con 
propiedad: hacer historia. "...el hecho de que la Historia no pueda ser pensada como "objeto» de un saber histórico o un concebir filosófico sino "como momento efectual del propio ser»" (Moratalla 1991 262), eso nos lleva a entender el sentido de la historia. Somos seres de acontecer históricos. Es innegable que esta visión de la historia se finca en la ontología de la finitud que somos, de donde se desprende que no hay cabida para conceptualizaciones totalizantes ni totalizadoras, sino parciales; lo cual no nos lleva necesariamente al relativismo. Situación paradójica que debe ser pensada.

En el debate que mantiene con Pannemberg respecto a la historia universal, la postura de Gadamer es clara: habrá que diferenciar entre la concepción cristiana de la historia y la visión filosófica. Agustín Domingo retoma unas palabras del mismo Gadamer en las que se puede ver la diferencia: " "Como toda la historia, la historia universal debe ser escrita siempre de nuevo, en la medida en que no posee un dato absoluto como la historia de la salvación, y todo proyecto de la misma no tiene una duración más larga que la de un relámpago que rasga por un momento la oscuridad del futuro y la del pasado que se pierde en el crepúsculo. Este es el núcleo de la filosofía hermenéutica que yo mismo me atreveré a defender frente a Hegel»." (Id. 263-264). Lo que nos habla tanto del carácter contingente de la historia como del mismo ser histórico que comprende la historia.

Gadamer, además, ratifica que no solamente todos los fenómenos de la comprensión, entendimiento e incomprensión, que son objetos de la hermenéutica, son un fenómeno del lenguaje, sino que la misma comprensión es lenguaje. La comprensión, con su diversidad de acepciones, no sólo acuña el entendimiento con el otro, sino asume la comprensión muda, silente, pues ésta "es el modo supremo e íntimo de comprensión" (1992 181). La comprensión también la pensamos generalmente en términos de entendimiento mutuo, sin embargo, cabe la observación de que el inicio de la comprensión está marcado por el no-entendimiento, es decir, cuando lo otro no cae dentro de los esquemas de nuestras expectativas. Pensemos, por ejemplo, en el asombro o en la admiración que son el inicio de un modo de comprensión nuevo. "Todo este desconcierto, asombro e incompatibilidad 
en la comprensión invita siempre a avanzar, a un conocimiento más profundo" (Id. 182). Pues, todo diálogo verdadero concluye en el acuerdo. Acuerdo que ya no se basa en mi opinión ni en la tuya, sino en la interpretación común de ese mundo. Este acuerdo intersubjetivo es lo que posibilita la solidaridad moral y social. "Lo que es justo y se considera tal, reclama de suyo la coincidencia que se alcanza en la comprensión recíproca de las personas" (Id. 185).

Habermas comenta que el texto de Gadamer, antes de titularse Verdad y método, título que verdaderamente abre camino al pensar filosófico, debió llamarse "Comprender y acontecer", por ser lo que expresa muy bien el pensamiento del autor: "...el comprender del intérprete «pertenece» a un acontecer que parte del texto menesteroso de interpretación." (Id.99). Esto quiere decir que el comprender sólo tiene sentido a partir de un texto sediento de interpretación, constituyéndose ésta en el mismo acontecer de la comprensión. Comprender e interpretar son el fenómeno del acontecer. La recuperación de la tradición, de lo "clásico", posibilita el acontecer de la interpretación que se actualiza en cada momento de la historia. El quebrantamiento de la unidad de la razón y su consecuente apertura a la pluralidad de interpretaciones pone en "tela de juicio" las pretensiones de universalidad de la verdad.

El reconocimiento de Habermas a la propuesta hermenéutica de Gadamer, concordante con los señalamientos anteriores, lo hace explícito en los siguientes términos: "El mejor desmentido de sus propias concepciones nos la ofrece el desplazamiento de paradigmas que tiene lugar por la praxis argumentativa del homenajeado mismo, que se mantiene joven y dispuesto a la discusión." (Id. 107). La renuncia o negación a este modo de proceder hermenéuticamente nos conduciría a asumir posturas dogmáticas y aberrantes, adversas a los caminos del pensamiento hechos práctica en la vida y obra de Gadamer.

Otra constante en el pensamiento de Gadamer, que viene a revolucionar el carácter cognitivo de la comprensión, es el sentido comunitario con el que se signa a la comprensión adquiriendo proyecciones universales. Los seres humanos somos constitutivamente seres de comprensión. Esta enlaza de tal forma a todo el género humano que 
quedamos "condicionados" a realizar nuestra existencia comunitariamente. Aquí no hay lugar para una existencia solitaria. ¿Quiere decir esto que es suficiente con reconocer el carácter comunitario de la comprensión para ser seres de comprensión signados por esta huella? Indudablemente que no. Este es el principio, pero no es el determinante para la existencia de seres comunitariamente comprensivos. La comprensión es un modo de ser que nos coloca en un estado de relación como seres de lenguaje, de diálogo, de comunicación, de acción, con miras a la realización de una vida comunitaria, justa, solidaria, responsable, etcétera. De donde se infiere el sentido ético de la comprensión.

Agustín Domingo comenta la expresión gadameriana: "El ser que puede ser comprendido es lenguaje" en los siguientes términos: "El lenguaje es el topos comunitario de la relacionalidad, en él se conforman la realidad y el entendimiento; de él debe partir nuestra reflexión sobre el ser, desde él adquiere carta de naturaleza ontológica (y no únicamente metodológica) el comprender" (Moratalla 1991 132). El lenguaje no es el medio por el que nos entendemos sino el lugar en el que vivimos, por el que somos una comunidad comunicativa. No se trata de una forma de comunicación, sino del modo de ser humanos: somos seres de comunicación, de diálogo. Podemos pensar que esta es la determinación originaria, que posibilita y da sentido a otras determinaciones que pretenden imponerse metodológica y científicamente con miras a fincar su universalidad, tal y como lo pretende la explicación científico-técnica de la realidad (a modo de ejemplo particular).

\section{El rebasamiento de los límites de la comprensión}

¿Por qué pensar la comprensión en estos términos? ¿Cuál es el propósito de rebasar los límites del conocimiento? ¿Será que al pensarla en términos originarios y existenciales enriquece el sentido de la vida humana? ¿Hasta dónde podemos vislumbrar sus alcances y expectativas? El punto de partida se establece cuando la pensamos más allá de un modo de conocer (metódico-epistemológico). 
El comprender como un existencial humano originario rebasa todo acto de conocimiento; en su sentido pleno se refiere a todo cuanto somos y hacemos, a la totalidad de nuestra vida. Es el modo de proyectar nuestra existencia. En tanto estructura humana originaria, constitutiva de nuestro ser y estar en el mundo, ineludiblemente es relación con la alteridad, pues con ella realizamos nuestro ser y estar en el mundo. Pensemos que la comprensión es así esa estructurara originaria del Dasein proyectada hacia posibilidades de realización en-el-mundo y con-el-mundo.

Así, pues, comprender no consiste en entender algo (reducción epistemológica) o poder hacer algo. La comprensión es la posibilidad de comprender nuestra propia existencia en dos posibilidades: a) la comprensión propia, a partir de nuestro modo de ser propio, nuestra interioridad, que es el modo de ser que nos corresponde, y b) la comprensión impropia, a partir de un modo de ser que no nos corresponde de manera propia: surge la crítica a la filosofía que ha conceptualizado al hombre a partir de los entes que están ahí, como objetos. Este comprender propio-impropio corresponde a la existencia propia e impropia como modos de ser originarios. En la existencia propia nos vemos a nosotros mismos como existencia, que es el modo de ser que nos corresponde, en relación con los otros: la solicitud es liberadora; en la impropia nos vemos como útiles u objetos, aquí la solicitud aparece como dominación, no liberadora. El paso de la existencia impropia a la existencia propia se da mediante el llamado de la conciencia-silenciosa. La existencia impropia se desenvuelve mediante la habladuría: "se dice", "curiosidad", no hay acercamiento al ser de la cosa; nos instalamos en la habladuría; tanto la habladuría como la curiosidad nos envuelven en la ambigüedad: no se es ni lo uno ni lo otro.

Si la comprensión no puede reducirse a un acto epistemológico, entonces ha de ser entendida como nuestra experiencia humana del mundo. Un ejemplo paradigmático de este modo de comprensión nos lo ofrece la experiencia de la verdad del arte y de la tradición histórica. Así lo ratifica Gadamer: "No es sólo que la tradición histórica y el orden de vida natural formen la unidad del mundo en que 
vivimos como hombres; el modo como nos experimentamos unos a otros y como experimentamos las tradiciones históricas y las condiciones naturales de nuestra existencia y de nuestro mundo forma un auténtico universo hermenéutico con respecto al cual nosotros no estamos encerrados entre barreras insuperables sino abiertos a él" (1984 26). Esta experiencia es individualmente única, particular, irrepetible e indispensable.

¿Cómo se inicia el esfuerzo hermenéutico del comprender? Gadamer establece un principio fundamental a modo de círculo hermenéutico: "comprender el todo desde lo individual y la individualidad desde la totalidad". Sin esta relación la comprensión se dirigiría por el camino de la incorrección: "El movimiento de la comprensión va constantemente del todo a la parte y de ésta al todo. La tarea es ampliar la unidad del sentido comprendido en círculos concéntricos. El criterio para la corrección de la comprensión es siempre la congruencia de cada detalle con el todo. Cuando no hay tal congruencia, esto significa que la comprensión ha fracasado" (Id. 361). El movimiento de ida y vuelta (individualidad-universalidad; universalidad-individualidad) no es algo circunstancial para la comprensión hermenéutica. Se requiere vigilancia, expectación y rigurosidad para no caer en interpretaciones equívocas o descontextualizadas. Gadamer analiza la siguiente propuesta de Dilthey y Schleiermacher, en la que ambos autores sostienen que: cada texto ha de ser comprendido desde sí mismo (Dilthey), es decir, desde su contexto (relación con el todo) y desde la vida psíquica del autor (Schleiermacher). Por lo que la comprensión sólo se lleva a término conjugando, en cada momento, ambos aspectos: tanto la naturaleza objetiva como la naturaleza subjetiva; proceso que, dice Gadamer, es necesario cuestionar, pues difícilmente se cumplen todos los aspectos, sobre todo los de naturaleza subjetiva. Es más, para Gadamer, la hermenéutica tiene como tarea explicar el milagro de la comprensión que no se realiza en la comunión misteriosa de las almas, sino en la participación en un sentido comunitario. En esto consiste, para Gadamer, entenderse en la "cosa misma" y, secundariamente, entender la opinión del otro. El punto de referencia es la cosa; el consenso es el carácter medial acerca del asunto de que se trata. Comprender la opinión del otro no es el asunto central, sino la "cosa 
misma". En estos términos la comprensión implica siempre acuerdos sobre la cosa y no sobre la diversidad de opiniones.

Agustín Domingo Moratalla cita el siguiente párrafo de Gadamer que nos abre caminos para entender qué es la comprensión. "Comprender es siempre comprender respecto de algo. Ya el lenguaje muestra que el «sobre qué» y el «en qué» no son objetos arbitrarios del discurso en sí mismo; (objetos) de los que la comprensión mutua pudiera prescindir al buscar su camino, sino que son más bien el camino y la meta (Weg und Ziel) del comprenderse mismo" (1991 121). En muchas ocasiones Gadamer insiste en direccionar la mirada y poder retornar constantemente a la "cosa misma", que se convierte en el lugar "sobre qué" y "en qué" se realiza el discurso. Por este camino se excluyen las arbitrariedades que se estancan en las opiniones individuales. La comprensión discursiva se finca en el diálogo comunitario que busca la comprensión mutua. En este escenario, se rebasa el carácter cognitivo de la comprensión y se abre al ámbito de nuestro modo de ser: experiencia de vida comunitaria, somos seres en-relación-con-elmundo y con-el-otro, así se entrelazan el mundo y la otredad a través del diálogo. Razón por la cual la hermenéutica apunta al lenguaje que va más allá de sí mismo y de lo que dice explícitamente. El sentido no se resuelve en lo que se expresa o verbaliza; lo cual no quiere decir que la expresión sea inexacta, sino que ésta trasciende lo que evoca y comunica. El lenguaje siempre lleva un sentido implícito, subyacente.

En el marco de la discusión entre objetividad y subjetividad, considero interesante presentar la polémica suscrita por Rorty acerca de qué sea la comprensión. Señala: por una parte, la orientación cientificista defendida por "los amigos de la técnica", que proponen como paradigma de comprensión la "...captación del mundo físico tal como la realizan, de modo creciente, las modernas ciencias naturales" (Gadamer 2003 47), y por otra los que sostienen que "todo cuanto puede ser comprendido es de naturaleza lingüística", en la que se ubica Gadamer, y que Rorty califica de nominalista, debido a que "...todas las entidades son de orden nominal, y todas las necesidades son de dicto" (Id. 45). La contradicción señalada a la primera postura la califica Rorty en los siguientes términos: "Es algo engañosa 
porque -al igual que la teoría de la verdad como correspondenciasugiere la idea de que es posible examinar las palabras por medio de algo que no sean palabras a fin de averiguar cuáles son las palabas apropiadas para el mundo" (Id. p.47). En cambio, la recuperación de la comprensión, en la segunda postura, abre la posibilidad para la comprensión de la cosa cada vez de manera distinta y novedosa, es decir, con la posibilidad de incorporar los sentidos que se le han asignado a través de la historia y el sentido actual. A este procedimiento Rorty lo denomina "nominalista", y coincide con lo que Gadamer llama "aumento de nuestra comprensión". Hablamos de la extensión de la comprensión, pero nos reservamos el calificativo de "mejor" o "peor", "mayor" o "menor", pues esta forma de denominación es una expresión del ejercicio de poder y dominación. Nuestra comprensión indudablemente puede mejorar, pero no ser mejor que la de los otros. Aquí el camino lo marca la cosa (Sache) que abre la posibilidad de ser comprendida de manera diferente e inagotable. En este ejercicio de comprensión cabe perfectamente el "dispositivo" dialogal que trasciende barreras religiosas, científicas, culturales, en fin, de "dominación". El siguiente parágrafo es una evidencia de la proyección de la comprensión gadameriana:

Desde los griegos hasta hoy, se ha solido caracterizar este proceso con ayuda de metáforas falogocéntricas de la profundidad. Según este modo de presentación, cuanto más hondo llega nuestra comprensión y más profundamente penetra en la cosa, tanto más nos alejamos de la apariencia y más nos acercamos a la realidad. Si tomamos el eslogan de Gadamer, el efecto es que esta metáfora de la amplitud: cuantas más descripciones haya en oferta y cuanto mejor estén integradas unas con otras, tanto mejor comprenderemos el objeto que estas descripciones nos transmiten (Id. 48-49).

Pero, sin ir más allá de estas pretensiones.

Para quienes gustan de ver a la comprensión hermenéutica como un acto exclusivo de la subjetividad Gadamer nos ofrece un concepto mucho más rico de la misma: "El comprender debe pensarse menos 
como una acción de la subjetividad que como un desplazarse uno mismo hacia un acontecer de la tradición, en el que el pasado y el presente se hallan en continua medición. Esto es lo que tiene que hacerse oír en la teoría hermenéutica, demasiado dominada hasta ahora por la idea de un procedimiento, de un método" (1984 360). Comprensión es un acto de mediación con la tradición. El comprender es la tarea y el compromiso de pensar y convivir con el ser en todas sus dimensiones y facetas. Su inicio lo marca la propia existencia (analítica de la existencia) y a partir de ahí la realización de todo el acontecer humano: comprender para ser.

De esta lectura y reflexión sobre el pensamiento gadameriano se pueden enunciar cinco formas de virtud hermenéuticas ${ }^{7}$ que se consideran indispensables para el modo de ser humanos, para la realización de la existencia, a saber:

1. La virtud de la apertura y la capacidad de escucha, que se hacen reales en el dejarse decir algo; solo quien está dispuesto a escuchar y dejarse decir algo puede entender y modificar su visión del mundo. El discurso abre esas dos posibilidades: hablar y escuchar. No solo hablar, aportar, también es necesario recibir. En relación con el texto, el escuchar se lleva a cabo cuando se deja hablar al texto; éste no es un objeto de manipulación. El texto tiene su propio sentido.

2. La segunda virtud consiste en reconocer que el otro puede tener razón. Se trata de comprender al otro, su mundo, su cultura, su vida, de manera que podamos reconocer o aceptar que son formas diversas de vivir y entender el mundo y que pueden tener la razón. La forma de entender al otro se lleva a cabo mediante la conversación que busca desembocar en el acuerdo donde las argumentaciones pueden encontrarse y reconocerse. "Lo que se trata de recoger es el derecho objetivo de su opinión a través del cual podremos ambos llegar a ponernos

7 Con ello no pretendemos afirmar o asegurar que sean las únicas virtudes hermenéuticas, sino las que nosotros, en esta lectura, hemos recuperado como necesarias. 
de acuerdo en la cosa. Por lo tanto, no referimos su opinión a su persona sino al propio opinar y entender" (Gadamer 1894 463). De este modo, se supera el riesgo del subjetivismo y se le concede un lugar al sentido (objetivo) de los interlocutores. La comprensión se da en el reconocimiento de lo que se dice, en el contenido de la conversación que se atiene al sentido objetivo de la misma y no a situaciones individuales en las que se hacen presentes las divergencias. "El ponerse de acuerdo en una conversación implica que los interlocutores están dispuestos a ello y que van a intentar hacer valer en sí mismos lo extraño y lo diverso" (Id. 465).

3. Muy cercana a la segunda virtud está ésta (tercera), que consiste en darle al otro validez frente a uno mismo. La comprensión no está sustentada en uno mismo, en la propia existencia, sino en el reconocimiento y aceptación del otro que es distinto de mí mismo. La diversidad o diferencia del otro, en oposición a uno mismo, se constituye en el refuerzo para la auténtica comprensión. Se busca la comprensión con sentido comunitario.

4. La cuarta virtud consiste en cuidad y defender al otro. Es decir, la exigencia está en reconocer y aceptar lo que el otro dice y vive. Gadamer afirma que el sentido pleno de la comprensión está en defender el asunto del otro.

5. La quinta virtud, de no menor importancia, consiste en descubrir y aceptar que la comprensión es recíproca. No se puede sesgar hacia los extremos: Yo-Tú o Sí mismo-el Otro. La virtud está en regresar a la palabra viva, al diálogo. El diálogo no es posible sin la intervención del Yo y del Tú, en el reconocimiento de ambos; ni solo Yo ni sólo Tú. El diálogo es el medio de la experiencia hermenéutica.

La comprensión también alcanza al lenguaje poético:

No obstante, cada poema del ciclo es una estructura de una precisión inequívoca; el que no sea transparente y de una claridad inmediata, no quiere decir que todo quede oculto o pueda significar cualquier cosa. Esta es la experiencia de 
lectura que hace el lector paciente. Sin duda, un lector apresurado no puede pretender comprender y descifrar la poesía hermética (Gadamer, 2001b, p. 11).

Encuentro que, en el comentario que Gadamer hace al poema de Celan, claramente manifiesta su postura respecto a la "comprensión" e "interpretación" de este poema, que no es sino la huella de toda su propuesta hermenéutica. Descifrar el "yo" y el "tú" en esta forma de expresión no es cosa sencilla ni fácil, tarea que Gadamer emprende con toda dedicación y paciencia. Con todo su bagaje cultural que le acompaña: "Toda comprensión presupone una respuesta a tal pregunta o, mejor dicho, una intuición superior y previa a la cuestión planteada" (Id.13). Después de los comentarios hechos por Gadamer a cada uno de los versos del poema nos ofrece un amplio Epílogo que nos enriquece y aclara lo que en algunos momentos dejó con dudas. La inclusión del Epílogo a la edición revisada muestra notables aportaciones respecto a la poesía de Celan.

\section{Algunas "conclusiones" reflexivas}

En la búsqueda y recorrido que se ha hecho de la hermenéutica gadameriana se juzga conveniente recuperar algunas de sus preocupaciones. a) Aquellos que ven en la filosofía hermenéutica la negación de la racionalidad metódica; b) algunos más ven en la hermenéutica una palabra de moda que usan superficialmente para llamar a cualquier tipo de comprensión e interpretación, hermenéutica; c) otros más la conciben como una propuesta de carácter metodológico, y d) los que pertenecen al bando de la crítica de la ideología que solo ven la verdad a medias. A ellos responde Gadamer llamándoles "fanáticos del método y críticos radicales de la ideología", a los que les hace falta reflexionar bastante sobre la verdad.

Otro aspecto importante que el autor propone dentro de la experiencia hermenéutica es el de historia-efectual, que se relaciona con la experiencia límite de nuestra autocomprensión y que tiene más de ser que de conciencia. 
También es oportuno reconocer una cierta problemática hermenéutica dentro del conocimiento de las ciencias naturales, que no se limita al procedimiento metodológico, tal y como ya lo había indicado Heidegger en su obra La época de la imagen del mundo.

La universalidad de la hermenéutica, propuesta por Schleiermacher, no tiene que ver sólo con la experiencia del arte, de la historia, de los textos, etcétera, sino se extiende a todo lo racional que puede ser objeto de acuerdo mutuo. Ante la diversidad de opiniones, los distanciamientos culturales, las confrontaciones ideológicas, etcétera, siempre se abre la posibilidad de un entendimiento común, que es la posibilidad de entendimiento entre los seres racionales. Bajo estos lineamientos, la reflexión hermenéutica nunca empieza de cero ni llega a su término definitivamente.

Cuando se afirma que el "método" propio de la hermenéutica es la comprensión, de ninguna manera se piensa en la observancia de reglas que nos aseguren el conocimiento. Esta forma de proceder debilitaría la comprensión y quedaría atrapada en el campo epistemológico. Afirmar que la comprensión es el "método" de la hermenéutica quiere decir que es nuestro modo de ser originario y existencial. Se podría sostener que se trata del tránsito de la hermenéutica clásica -normativa-, como metodología de la interpretación, a la hermenéutica filosófica orientada hacia la verdad, como posibilidad de encuentro con las "cosas mismas". Este recorrido se puede sintetizar como el carácter existencial de la comprensión, en el que el objetivo ya no consiste en la aprehensión de la realidad sino en el encuentro vivencial-experiencial con la cosa. Este modo de relacionarnos existencialmente con las cosas se entiende como un encuentro, que es donde se introduce el "tema" de la verdad. De donde se desprende que la verdad se convierte en el eje que atraviesa su gran obra Verdad y método, en la cual, en una primera parte es pensada desde la experiencia del arte; en una segunda, en las ciencias del espíritu, y en una tercera el carácter ontológico del lenguaje es el hilo conductor de la verdad. En este sentido podemos afirmar que la verdad asume un carácter existencial, sin quedar sujeta a las reglas de la discusión lógica o epistemológica. 
Un punto de vista fundamental para la hermenéutica filosófica, en la búsqueda del sentido originario, es que no existe la correspondencia o identidad entre lenguaje, pensamiento y ser. En esta relación, ciertamente, se produce un desocultamiento pero, a la vez, algo permanece velado. El lenguaje no es un instrumento usado por el pensamiento para describir la realidad. El ser tampoco es un objeto sin más que pueda ser apresado por el pensamiento. Ser, pensar y hablar son realidades que se encuentran interrelacionadas armónicamente, es decir, que no pueden desarticularse arbitrariamente; una presupone a las otras, y así sucesivamente. Gadamer privilegia la dimensión del lenguaje con su carácter ontológico. Si hablamos y pensamos acerca del ser, es decir, lo interpretamos, es porque éste se encuentra en el ámbito del lenguaje.

Al principio hermenéutico de que "el todo debe entenderse desde lo individual y lo individual desde el todo" lo llamamos el arte del comprender. Pero, la unidad de sentido comprendida no es acabada ni absoluta, sino debe ampliarse en círculos concéntricos buscando la confluencia de todos los elementos que conforman la comprensión. La falta de esa confluencia determina el fracaso de la comprensión. Es precisamente el descubrimiento del significado común el que nos permite acordar en la cosa. De ahí que la interpretación correcta debe alejarse de las ocurrencias arbitrarias que nos distancian de las cosas mismas. Y, del mismo modo debe apelarse al texto, recuperando el concepto de alteridad, es decir, lo que el texto nos dice, no la opinión, no las ocurrencias, sino la realidad (que no es un dato empírico sino de sentido). Comprender, así, no es otra cosa que habérselas con las cosas mismas que nos interpelan, nos llaman la atención, nos dicen. Es tarea del hermeneuta estar atento a los que las cosas dicen y saber formular preguntas y dialogar con el otro sobre las cosas.

Para finalizar, Antonio Gómez Ramos, traductor y prologuista de la obra El ser que puede ser comprendido es lenguaje. Homenaje a HansGeorg Gadamer, se refiere a Rüdiger Bubner como el "discípulo aventajadísimo" de Gadamer. Es Bubner, precisamente, quien, en un brevísimo texto titulado "El daimon intérprete", aprovecha la ocasión para hacer un elocuente reconocimiento y rendir homenaje 
al "maestro" Gadamer. De manera brillante y por demás comprometedora se refiere a la sublime misión del hermeneuta. Es a éste a quien le compete ser el daimon entre los dioses y los mortales. Ejercer esta tarea consiste en traer el mensaje de los dioses a los hombres y llevar las súplicas, oraciones y sacrificios de éstos a los dioses. Es el artífice de este puente quien hace la función mediadora entre los dioses y los hombres. Este daimon no se refiere, en ningún modo, a la fuerza demoniaca, sino al buen espíritu e ingenio del intérprete que hace factible esta misión, pero sin ascender al rango de lo divino. Con las siguientes palabras Bubner elogia el quehacer hermenéutico de Gadamer, reconociéndole como 'un sophos daimonnios aner, un hombre sabio, agraciado por el daimon' (2003 21). Palabras que encuentran eco tanto en la vida como en la obra de Gadamer. Es suficiente con tener a la mano su propuesta de "hermenéutica dialógica" para hacer patente la presencia del daimon que le inspira en la búsqueda de la verdad. Jamás con pretensiones de dominio o desconocimiento de las razones del otro.

\section{Bibliografía}

Figal, G. "Fenomenología de la cultura. Verdad y método después de cuarenta años", en Habermas, J. y otros El ser que puede ser comprendido es lenguaje. Homenaje a Hans-Georg Gadamer. Madrid: Trotta, 2003.

Gadamer, H. G. Verdad y método. Fundamentos de una hermenéutica filosófica. Salamanca: Sígueme, 1984.

Gadamer, H. G. Verdad y método II. Salamanca: Sígueme, 1992.

Gadamer, H. G. El giro hermenéutico. Madrid: Cátedra, 1998.

Gadamer, H. G. Antología. Salamanca: Sígueme, 2001.

Gadamer, H. G. ¿Quién soy yo y quién eres tú? Comentario a "Cristal de aliento" de Paul Celan. Barcelona: Herder, 2001b.

Grondin, J. Introducción a Gadamer. España: Herder, 2003.

Habermas, J. y otros. El ser que puede ser comprendido es lenguaje. Homenaje a Hans-Georg Gadamer. Madrid: Trotta, 2003.

Heidegger, M. Ser y tiempo, Madrid: Trotta, 2003. 
López Sáenz, M ${ }^{\text {a }}$ C. Corrientes actuales de la filosofía I. En-clave fenomenológica. Madrid: Dykinson, 2012.

Maceiras, M. y Trebolle, J. La hermenéutica contemporánea. Bogotá: Cincel, 1990.

Moratalla, Agustín Domingo. El arte de poder no tener razón. La hermenéutica dialógica de H. G. Gadamer. Salamanca: Universidad Pontificia, 1991.

Silva, J. M. (2002) "Hans-Georg Gadamer (1900-2002) In memoriam. El arte de comprender y de hacer comprender". La lámpara de Diógenes, Revista de filosofía 3/5 (enero-junio 2002): 45-51. 